\title{
Assessment of the occupational dose and radiogenic risk in diagnostic radiology and nuclear medicine examinations
}

\author{
M.K. Saeed ${ }^{1^{*}}$ and Y. Almalki ${ }^{2}$ \\ ${ }^{1}$ Department of Radiological Sciences, Applied Medical Sciences College, Najran University, Najran, Saudi Arabia \\ ${ }^{2}$ Division of Radiology, College of Medicine, Najran University, Najran, Saudi Arabia
}

\section{- Original article}

*Corresponding authors:
Mohamedrick Saeed, PhD.,
E-mail:
$\quad$ mohamedrick@gmail.com
Revised: March 2020
Accepted: June 2020
Int. J. Radiat. Res., April 2021;
19(2): 365-372
DOI: 10.29252/ijrr.19.2.357

\begin{abstract}
Background: With the rapid development of medical imaging equipment and applications of radioactive substances in the diagnosis and treatment of diseases, the exposure of staff and patients to radiation doses becomes increasingly an alarming issue. Materials and Methods: This study aimed at estimating the effective dose during radiologic and nuclear medicine examinations of patients, based on their administered dose activity. In parallel, the staff doses were also assessed using thermoluminescent dosimeters (TLDs). The staff members, specifically dealing with $99 \mathrm{mTc}$, were also investigated for their eye lens dose exposure and radiogenic risk. Results: The mean of occupational annual dose for the whole body, $\mathrm{Hp}(10)$, during the examinations of standard radiography, computed tomography (CT), interventional cardiology, and nuclear medicine were estimated to be 0.33 , $0.31,0.81$, and $11.6 \mathrm{mSv}$, respectively. The annual exposure of eye lens dose, $\mathrm{Hp}(3)$, from ${ }^{99 \mathrm{~m}} \mathrm{Tc}$ medicine examinations ranged from 4.9 to $11.8 \mathrm{mSv}$. Conclusion: In this study, the $\mathrm{Hp}(3)$ for medical staff, at the nuclear medicine department, was evaluated by measuring the $\mathrm{Hp}(10)$. The doses reported in this study were interestingly found to be less than the annual dose limits recommended by the concerned international organizations.
\end{abstract}

Keywords: Effective dose, radiology, nuclear medicine, eye-lens.

\section{INTRODUCTION}

The advent of contemporary medical imaging equipment and applications of radioactive isotopes in nuclear medicine in the past decade resulted in more accurate diagnosis of diseases and injuries. However, using ionizing radiation such as gamma or X-rays is inevitably associated with radiogenic risk. Accordingly, the assessment of radiation doses inflicted on radiology staff personnel is increasingly becoming an important issue. The International Commission on Radiological Protection (ICRP) and the National Council on Radiation Protection and Measurements (NCRP) issue joint periodical reports regarding safety recommendations for the radiology staff and the public at large. These recommendations aim at optimizing the therapeutic or diagnostic dose.

Radiation damage to tissue and/or organs depends on several factors such as the amount and type of radiation and the possible sensitivities of different tissues and organs to radiation. Attention should be drawn to the fact that even low doses levels of ionizing radiation can increase the risk of long-term effects such as cancer (1). The effective dose was introduced by the ICRP in 1991 (2) to estimate the ionizing radiation dose in terms of the potential for causing a stochastic health risk. In addition, in 1995, the NCRP issued recommendations regarding the practice and the use of personal monitors to estimate the effective radiation dose for individuals mainly exposed to low linear energy transfer (LET) radiation (3).

Currently, about 377 million diagnostic and 
interventional radiologic examinations were performed in the United States (4). In addition, over 100 procedures are used in nuclear medicine and it has been estimated that by the first decade of the twenty-first century in excess of 20 million procedures were being performed in the United States annually (4,5). Nuclear medicine provides unique information for different body organs that often cannot be obtained using other sectional imaging modalities. However, the procedures of Nuclear medicine put staff and patients at risk of radiation exposure, which may prompt increment in the probability of cancer induction (6). Reported mean values of the effective dose approximately range between $0.01-10,2-20,5-$ 70 , and $0.3-20 \mathrm{mSv}$ for standard radiography, $\mathrm{CT}$, various interventional radiology and nuclear medicine procedures respectively (7). Regarding staff doses in nuclear medicine procedures Gadhi et al. (8), have estimated the highest annual dose to be $4.95 \mathrm{mSv}$. Regarding patient doses, Javadi et al. (9), have estimated the average patient effective dose to be $4.0 \mathrm{mSv}$ per diagnostic nuclear medicine procedure. The authors revealed bone scans and cardiac scans to give rise to greater radiation doses compared to that of other procedures. According to Xiao-San et al. (10), in a study in China, in using a retrospective dosimetry method the average annual effective dose for staff resulting from diagnostic radiology procedures for the period of 1996-2011 was found to be $1.1 \mathrm{mSv}$. In Kuwait, the mean annual dose reported for the diagnostic radiology and nuclear medicine staff was 1.05 and $1.07 \mathrm{mSv}$ respectively (11). Reported doses were all below annual limits for workers (effective dose limit of $20.0 \mathrm{mSv}$ ).

The ICRP recommended the ambient dose and directional dose equivalent as operational quantities for assessing the effective dose at variable depths. Whereas, the depth dose Hp (10), Hp(0,07), Hp (3) assessing the effective dose for whole body, skin and eye lens respectively $(12,13)$. However, the procedure of monitor the equivalent dose to the lens of the eye at $3 \mathrm{~mm}$ depth may be impractical. Accordingly, the ICRP authorized using depth dose of $\operatorname{Hp}(0,07)$ in case the lack of monitoring device designed to measure $H p(3)$ (13). Other methods have been used to assessing the $\mathrm{Hp}(3)$ such as evaluating the $\mathrm{Hp}(10)$ and $\mathrm{Hp}(3)$. One of these methods suggested by Kopec et al. based on studying the relationship between doses of the entire body, limbs, and eye lenses of medical staff in nuclear medicine (14). They reported that the $\mathrm{Hp}(3)$ for medical staff at nuclear medicine departments could be estimated from measuring the $\mathrm{Hp}(10)$ with a ratio range between 0.7 and 1.1 for technical staff (14).

It should be noted that the ICRP has issued a statement in 2011 decreasing the limit of the dose to the eye lens for occupational works to a mean value of $20 \mathrm{mSv} / \mathrm{y}$ averaged over a defined period of five years provided not more than 50 mSv per single year (15). Thus, the new limit was lower by a factor of almost 8 . This trend could probably be attributed to the lens of the eye may be more radiosensitive than previously assumed (16).

Recently, Sulieman et al. evaluated the effective dose for staff working with $99 \mathrm{mTc}$ nuclear medicine examinations (17). As a continuation of this effort, this work evaluated the effective dose and radiogenic risk associated with diagnostic radiology and nuclear medicine examinations. In addition, the medical staff, specifically dealing with $99 \mathrm{mTc}$, were also investigated for their eye lens dose exposure.

\section{MATERIALS AND METHODS}

\section{Occupational dosimetry}

Staff members in diagnostic radiology and nuclear medicine departments are routinely monitored using TLDs. Usually, two-dose quantities, i.e. the $H p(10)$ and the $H p(0.07)$ are measured every three months for each staff member. The staff members were divided into five groups as follows: general $\mathrm{x}$-ray technologists (GxTs), CT technologists (CTTs), interventional radiology technologists, radiologists (Rads), and nuclear medicine technologists (preparation and/or operator). Other staff professions such as nursing were not included in this study. Ethical authorization was received from the University ethics committee in 
Jan 2017 (Registration number: 05-10-1-17EC).

Dose assessment was performed using GR-200A TLDs (LiF: $\mathrm{Mg}, \mathrm{Cu}, \mathrm{P}$ ) (PTW, Germany). All TLDs used are circular chips of dimension $0.8 \mathrm{~mm}$ thickness by $4.5 \mathrm{~mm}$ diameter. The Fimel PCL3 TLD reader (France) was used for readout of the TLD signals and were annealed by heating at $240^{\circ} \mathrm{C}$ for $10 \mathrm{~min}$ followed by fast cooling using the computed oven (TLDO; PTW, Freiburg, Germany). Individual calibration factors were obtained for all TLD chips. TLD calibration was carried out according to international protocols for the range of energies used in the study.

\section{Staff dose in diagnostic radiology}

Over a period of two years, the occupational doses associated with standard radiographic, CT, coronary angiography (CA), and percutaneous transluminal coronary angioplasty (PTCA) examinations were investigated. The patients' demographic data (the age and gender) and examinations were presented in table 1.

Table 1. The distribution of patients' undergoing diagnostic radiology examinations during the period from 2017 to 2018.

\begin{tabular}{|c|c|c|c|c|}
\hline & $\begin{array}{c}\text { Total number } \\
\text { of patients }\end{array}$ & $\begin{array}{c}\text { Mean of patients } \\
\text { age (years) }\end{array}$ & $\begin{array}{c}\text { Male } \\
\text { patients }\end{array}$ & $\begin{array}{c}\text { Female } \\
\text { patients }\end{array}$ \\
\hline X-ray & 5232 & 42 & 3720 & 1512 \\
\hline CT & 3210 & 36 & 2130 & 1080 \\
\hline CA & 480 & 52 & 290 & 190 \\
\hline PTCA & 192 & 48 & 110 & 82 \\
\hline
\end{tabular}

The annual effective dose was measured for 4 technologists during their daily practice in two $\mathrm{x}$ -rays units (Toshiba DRX-3724HD and GE AL01F), and for six technologists dealing with two CT scanners. One of the CT scanners applied in this study is from Hitachi (Scenaria) and the other from GE (Hi-Speed Dual). Both scanners are installed between the periods from 2013 to 2015. The features of Hitachi (Scenaria) 64-slice CT scanners include $0.35 \mathrm{~s}$ per rotation scanning of any part of the whole body and low dose examinations by using exposure dose optimization together with maintaining a selected noise.

Further, the radiation dose to three technologists was also measured during their daily practice in CA and PTCA unit (Innova 2000, General Electric (GE), Milwaukee WI, USA), seeking to assess their annual effective dose.

\section{Staff and patients dose in nuclear medicine}

Over a period of 9 weeks, doses arising from studies of patients undergoing bone, thyroid, renal and liver-spleen nuclear medicine procedures were investigated. The effective dose (in $\mathrm{mSv} / \mathrm{MBq}$ ) reported by the ICRP in 1998 (18) was used in this study with the administered $99 \mathrm{~m}$ Tc radiopharmaceutical activity to calculate the effective dose in $\mathrm{mSv}$. According to the patient weight, the administrated activities was ranged between 740-1295 MBq, 111-185 MBq, 111-222 MBq, and 37-296 MBq for bone, renal, thyroid, and liver-spleen imaging, respectively.

The $99 \mathrm{mTc}$ generators used were purchased from TechneLite (Lantheus Medical Imaging, Inc. Canada). The choice of $99 \mathrm{mTc}$ was based on a number of factors such as short physical half-life $(\approx 6 \mathrm{~h})$, short imaging times, inexpensive, and has gamma emission which is predominately $140 \mathrm{keV}(89.1 \%)$. In this study, the $99 \mathrm{~m}$ Tc-sodium pertechnetate), ${ }_{99 \mathrm{~m} T c}$-diethylenetriamine pentaacetic acid ${ }^{99 \mathrm{~m}} \mathrm{Tc}$ DTPA) and $99 \mathrm{mTc}$-sulfur colloid were used for thyroid, bone, renal and liver-spleen imaging, respectively. The nuclear medicine imaging was performed using a dual-head coincidence gamma camera provided by $\mathrm{NaI}(\mathrm{Tl})$ crystals of 5/8-inch thick (VariCam, Elscint).

The radiogenic risk for thyroid, renal, bone and liver-spleen scan procedure was determined using the conversion factor of the cancer risk reported by ICRP (2). In addition, the occupational exposure was evaluated using a calibrated survey meter $(451 \mathrm{P}$ Ion Chamber Fluke Victoreen, USA) at different locations in the nuclear medicine department. On the other hand, TLDs mentioned previously were used to estimate the staff effective dose, Hp (0.07) and $\mathrm{Hp}(10)$.

As previously mentioned, the eye lens considered one of the radiosensitive organs and recognized to be potentially exposed to significant doses in nuclear medicine departments. Therefore, the dose assessment was managed through developing software to 
estimate the effective doses and equivalent-doses to the eye using tissue weighting factors according to the method that has been described previously (3). The staff was divided into two groups. The first group responsible for escorting, and positioning the patient in the gamma camera (operation group). However, the second group involved the technical staff whose duties include preparing the elution of $99 \mathrm{mTc}$ from $99 \mathrm{mTc} /{ }^{99 \mathrm{~m} M o}$ generators (preparation group).

The $\mathrm{Hp}(3)$ was calculated based on the equations (1) and (2) as reported by Kopec et al. (14).

$\mathrm{Hp}(3)=(1.1 \pm 0.2) \times \mathrm{Hp}(10)$
$\mathrm{Hp}(3)=(0.7 \pm 0.1) \times \mathrm{Hp}_{x}(10)$

where $H p(76)$ was used to represent the dose per month for the preparation group. $\mathrm{Hp}_{x}(10)$ is the dose per month for the operation group.

All statistics were calculated using either Microsoft Office Excel 2013 (Microsoft Inc, Redmond, WA) and/or the SPSS version 14 (SPSS Inc, Chicago, IL). A two-sample t-test was used to analyze the study results.

\section{RESULTS}

\section{Doses in the department of nuclear medicine}

A total of 450 patients referred for bone, thyroid, renal and liver-spleen examinations in the nuclear medicine were studied. Over a period of 9 weeks, doses arising from patients were investigated for common nuclear medicine procedures as presented in table 3 . The variation of patient doses shown in table 3 may be attributed to variation in patient weights and clinical conditions.

Table 4 shows the mean ambient dose measured in the trash container, waiting room, hot-lab, and injection room. It can be seen that the maximum dose rate value detected in the hot lab. These results were expected because hot lab room is specially designed in a nuclear medicine hospital where the radiopharmaceuticals are delivered, stored and prepared for dispensing. The dose rate in hot-lab found to be higher than other locations with factor ranges from 1.0 to 24 .

The annual effective doses for the whole body were $7.2 \mathrm{mSv}$ and $11.6 \mathrm{mSv}$ for the operation and preparation groups, respectively (table 5). Both results of $\mathrm{Hp}(10)$ and $\mathrm{Hp}_{\mathrm{x}}(10)$ were significantly below the annual limits with 58 to $36 \%$, respectively. Table 5 also shows the results of eye lens dose measured, $\mathrm{Hp}(0.07)$, and calculated, $\mathrm{Hp}(3)$, for the two technologist groups (preparation and operator). The variation factors between the annual $\mathrm{Hp}(3)$ and the $\operatorname{Hp}(0.07)$ are 1.0 and 1.1 for operator and preparation groups, respectively. It can be observed that the measured values of annual eye lens doses for operator group reported in this study were lower 4 times than the eye dose limit.

Table 2. Annual occupational doses.

\begin{tabular}{|c|c|c|c|c|c|c|c|}
\hline \multirow{2}{*}{ Group } & \multirow{2}{*}{ Year } & \multicolumn{3}{|c}{$\mathrm{Hp}(0.07) \mathrm{mSv}$} & \multicolumn{3}{c|}{$\mathrm{Hp}(10) \mathrm{mSv}$} \\
\cline { 3 - 9 } & & Min* $^{*}$ & Max* & Mean & Min* & Max* & Mean \\
\hline \multirow{3}{*}{ GxTs } & 2017 & 0.16 & 0.57 & 0.31 & 0.08 & 0.61 & 0.32 \\
\cline { 2 - 9 } & 2018 & 0.17 & 0.52 & 0.37 & 0.07 & 0.59 & 0.35 \\
\hline \multirow{3}{*}{ CTTs } & 2017 & 0.04 & 7.45 & 0.35 & 0.04 & 7.21 & 0.32 \\
\cline { 2 - 9 } & 2018 & 0.03 & 6.31 & 0.29 & 0.02 & 6.16 & 0.27 \\
\hline \multirow{3}{*}{ PTCATs* } & 2017 & 0.24 & 0.98 & 0.87 & 0.23 & 0.86 & 0.88 \\
\cline { 2 - 9 } & 2018 & 0.23 & 1.02 & 0.86 & 0.22 & 1.01 & 0.87 \\
\hline \multirow{2}{*}{ CATs* } & 2017 & 0.13 & 0.82 & 0.73 & 0.11 & 0.71 & 0.72 \\
\cline { 2 - 8 } & 2018 & 0.12 & 0.93 & 0.79 & 0.15 & 0.93 & 0.73 \\
\hline \multirow{2}{*}{ Rads } & 2017 & 0.08 & 1.04 & 0.46 & 0.05 & 0.98 & 0.45 \\
\cline { 2 - 8 } & 2018 & 0.12 & 0.99 & 0.51 & 0.03 & 0.93 & 0.51 \\
\hline
\end{tabular}

*PTCATs, PTCA technologists; CATs, CA technologists; Min, minimum; Max, maximum. 
Table 3. Radiogenic risk and effective dose for patients undergoing bone, thyroid, renal, and liver-spleen nuclear medicine examinations.

\begin{tabular}{|c|c|c|c|c|c|c|c|c|c|}
\hline \multirow{2}{*}{ Scan } & \multirow{2}{*}{$\begin{array}{c}\text { Number of } \\
\text { patients }\end{array}$} & $\begin{array}{c}\text { Effective dose } \\
\text { (mSv/MBq) }\end{array}$ & \multicolumn{3}{|c|}{ Activity (MBq) } & \multicolumn{3}{|c|}{ Effective dose (mSv) $^{\text {Mean cancer risk }}$} \\
\cline { 3 - 11 } probability $^{* *}$
\end{tabular}

${ }^{*}$ Min, minimum; Max, maximum. ${ }^{* *}$ per 1 million procedures (x 10-6)

Table 4. Average of ambient dose at a different location in the nuclear medicine department.

\begin{tabular}{|c|c|c|c|}
\hline \multirow{2}{*}{ Location } & \multicolumn{3}{|c|}{ Dose rate $(\boldsymbol{\mu S} \mathbf{/ h})$} \\
\cline { 2 - 4 } & Min & Max & Mean \\
\hline Trash container & 9 & 450 & 20 \\
\hline Waiting room & 67 & 230 & 85 \\
\hline Hot-lab & 35 & 450 & 95 \\
\hline Injection room & 2 & 2 & 4 \\
\hline
\end{tabular}

\section{DISCUSSION}

It was mentioned in the materials and methods section, that the occupational dose was measured during the various stages of daily routine examinations in the Department of Radiology to assess, first, the effectiveness of current preventive measures and, second, the associated risks of radiation. The disparity in the range of occupational dose in this study as compared to that reported in other studies may be due to the variations in the daily tasks and the workload of the staff (19-20). In addition, radiographic exposure has a direct effect on, first, the quality of the represented image and, second, the amount of dose delivered to the patient and/or medical staff in any routine radiographic examination. Furthermore, both the effective dose and the accuracy of diagnosis may be influenced by either a lower or a higher dose of radiation. Therefore, for a proper radiographic diagnosis, patients should be exposed to the adequate dose of radiation which should be determined accurately (21).

The PTCA is considered one of the high-dose cardiology procedures (22). One of the positive aspects of this study is that most of the diagnostic radiation technologists adhere
Table 5. Staff dose (in mSv) in the surveyed nuclear medicine department.

\begin{tabular}{|c|c|c|}
\hline Occupational Dose & Annual dose & Dose per month \\
\hline $\mathrm{Hp}(10)$ & $11.6 \pm 0.10$ & 0.97 \\
\hline $\mathrm{Hp}(10)$ & $7.2 \pm 0.13$ & 0.60 \\
\hline Eye dose $\mathrm{Hp}(0.07)^{*}$ & $4.9 \pm 0.12$ & 0.41 \\
\hline Eye dose $\mathrm{Hp}(0.07)$ & $11.8 \pm 0.11$ & 0.98 \\
\hline Eye dose $\mathrm{Hp}(3)$ & $12.8 \pm 0.20$ & 1.07 \\
\hline Eye dose $\mathrm{Hp}(3)^{*}$ & $5.0 \pm 0.10$ & 0.42 \\
\hline
\end{tabular}

*Eye lens dose for the operator staff.

strictly to the rules and regulations of protection against accidental exposure to radiation. For instance, lead apron, gloves, lead glass, and thyroid shields are worn by the technologists on a regular basis prior to every radiologic investigation of patients. This is to the contrary of their counterparts who work in the departments of CT and conventional x-ray. However, the doses of interventional cardiology, shown in table 2, are higher than those in other radiology groups such as GxTs, CTTs and Rads. This may due to the fact that the radiologic procedures in this study take longer time and involve closer contact with the patients as compared to those in other radiology groups. The mean annual occupational doses for GxTs, CTTs and Rads groups in this study ranged between 0.27 and $0.51 \mathrm{mSv}$ (table 2). These results are in general agreement with those obtained by other workers from Saudi Arabia (19). In addition, another comparison of the mean annual effective doses of radiology in the present study with other reports is shown in table 6 . The results obtained in this study are also in general agreement with those reported in Pakistan (23) and Ghana (24), however, they are lower than those in China (25) and Greece (26) with a factor of up to 7.3. The variations in the 
annual effective doses shown in Table 6 may be attributed to several factors such as the relatively high workload assigned to the technicians and implementation of the quality control program.

Table 6. Comparison of average annual effective doses in nuclear medicine and radiology in the present study with literature.

\begin{tabular}{|c|c|c|c|}
\hline Period & Country & $\begin{array}{c}\text { Nuclear } \\
\text { Medicine (mSv) }\end{array}$ & $\begin{array}{c}\text { Diagnostic } \\
\text { Radiology (mSv) }\end{array}$ \\
\hline $\begin{array}{c}\text { Current } \\
\text { study }\end{array}$ & $\begin{array}{c}\text { Saudi } \\
\text { Arabia }\end{array}$ & $\begin{array}{c}11.60^{*} \\
7.2^{* *}\end{array}$ & 0.53 \\
\hline $2000-2009$ & Ghana $^{(24)}$ & 0.63 & 0.76 \\
\hline $1986-2000$ & China $^{(25)}$ & 1.40 & 1.85 \\
\hline $1994-1998$ & Greece $^{(26)}$ & 2.27 & 3.86 \\
\hline $1991-2007$ & Poland $^{(27)}$ & 2.47 & - \\
\hline $2007-2011$ & Pakistan $^{(23)}$ & 1.12 & 0.52 \\
\hline 2018 & Sudan & \\
\hline
\end{tabular}

The assessment of the annual equivalent dose for nurses was not performed in this study which is one of its limitations. However, the nurse's group may be overexposed to large doses of radiation because of the excessive workload. Unfortunately, information regarding the amount of dose for the nurses was lost. In addition, the exposure mode may also be considered as one of the limitations of this study, where all radiology staff was monitored with TLD, which received the radiation from one direction directed up towards the chest area. To overcome this drawback, it was suggested to perform a pair of simultaneous TLDs measurements instead of one (28). Probably, the use of two dosimeters may be financially costly and exhausting when examining large numbers of staff.

As regards the dose assessment in nuclear medicine and the relevant associated radiation risks, it's important to evaluate the effective doses that occur during each procedure. Therefore, when thirty nuclear medicine procedures were evaluated, four scans for patients were performed for patients undergoing bone, thyroid, renal, and liver-spleen examinations. The estimated effective dose ranged from 0.35 to $7.38 \mathrm{mSv}$. It is worth mentioning that the bone scans give rise to greater radiation doses compared to that of other procedures .In general, these results were higher by a factor of 4.5 than the values of renal scan dose in another study (17). This contradiction may be due to the variations of patients' weights and numbers as well as clinical indications. Furthermore, the cancer risk probability per procedure is greatest for bone scans due to the larger administered activities. For the sake of more clarification, table 6 present a comparison between the average annual occupational dose in nuclear medicine obtained in this work and literature $(17,23-7)$. It is evident, from Table 6 that the value reported in this study are comparable with data reported in Sudan ${ }^{(17)}$ and higher than the values reported in other countries. Variation of occupational exposure depend on staff duties and the wide discrepancies between staff doses suggest that poor adherence to department protocol.

The disparity of the ambient doses shown in Table 4 can be changed periodically accordingly to administrated activities and types of scanned procedures. For example, bone scans are performed using large administrated activity comparing to renal and thyroid scans. The time between the injection and scan varies, and the patients required one to four hours later to allow the tracer to circulate and be absorbed by patients bones. The administrated activity in the bone scan varying between renal and thyroid scans by a factor up to 6 , accordingly, the dose received by workers expected to increases as activity increase and this certainly will affect the ambient dose.

With the support of direct estimate of $\mathrm{Hp}$ $(0,07)$ of the preparation and operator groups and comparison with the computed dose of $\mathrm{Hp}$ (3) (table 5), we suggest that eye lens dose of $\mathrm{Hp}$ (3) could probably be evaluated from measurements of $\mathrm{Hp}(10)$. It can also be measured directly from the $\operatorname{Hp}(0,07)$ in case the lack of monitoring device designed to measure $\mathrm{Hp}(3)$. It is worth mentioning that the selection of Kopec et al. (14) ratios, which previously mentioned in equations (1) and (2) to calculate $\mathrm{Hp}(3)$, count on nuclear medicine technologists that mostly handling $99 \mathrm{~m}$ Tc. Based on our doses results of the eye lens, we believe that the

Int. J. Radiat. Res., Vol. 19 No. 1, April 2021 
analysis of the measured doses and comparing them with the different radiation doses can provide valuable information in improving the quality of radiation protection.

\section{CONCLUSION}

This study investigated the staff and patient effective doses in diagnostic radiology and nuclear medicine departments. The occupational doses of $\mathrm{Hp}(0.07)$ and $\mathrm{Hp}(10)$ at the two departments were found to be less than the annual dose limit reported by the ICRP. The eye lens doses were also found within the recommended limits. Further measures are needed to ensure that nuclear medicine team members and patients will not be exposed to unnecessary dose. In case the lack of monitoring device designed to measure $\mathrm{Hp}(3)$, dose measurements using an indirect method provided in this study are recommended.

\section{ACKNOWLEDGEMENT}

The authors would like to thank the co-operation of the Najran University Hospital Directorate, the radiologists and technologists from the Radiology Department and nuclear medicine departments participating in this study.

Funding: This study was funded by the Scientific Research Deanship of Najran University (Grant No. NU/MID/16/011).

\section{Conflicts of interest: Declared none.}

\section{REFERENCES}

1. Upton AC, Shore RE, and Harley NH (1992) The health effects of low-level ionizing radiation. Annu Rev Publ Health, 13: 127-150.

2. International Commission on Radiological Protection ICRP (2007) The 2007 recommendations of the international commission on radiological protection. ICRP Publication 103, Pergamon Press, Oxford.

Int. J. Radiat. Res., Vol. 19 No. 2, April 2021
3. National Council on Radiation Protection and Measurements NCRP (1995) Use of personal monitors to estimate effective dose equivalent and effective dose to workers for external exposure to low LET radiation. NCRP Report No. 122, Bethesda, USA.

4. Mettler FA, Bhargavan M, Faulkner K, Gilley DB, Gray JE, Ibbott GS, Lipoti JA, Mahesh M, McCrohan JL, Stabin MG, Thomadsen BR, Yoshizumi TT (2009) Radiologic and nuclear medicine studies in the United States and worldwide: frequency, radiation dose, and comparison with other radiation sources-1950-2007. Radiology 253: 520-531.

5. Sudbrock F, Uhrhan K, Rimpler A, Schicha H (2011) Dose and dose rate measurements for radiation exposure scenarios in nuclear medicine. Radiat Meas, 46(11): 13031306.

6. Alnaaimi $\mathrm{M}$, Alkhorayef $\mathrm{M}$, Omar $\mathrm{M}$, Abughaith $\mathrm{N}$, Alduaij M, Salahudin T, Alkandri F, Sulieman A, Bradley D (2017) Occupational radiation exposure in nuclear medicine department in Kuwait. Radiat Phys Chem, 140: 233-236.

7. Mettler FA, Huda W, Yoshizumi TT, Mahesh M (2008) Effective doses in radiology and diagnostic nuclear medicine: a catalog. Radiology, 248(1): 63-254.

8. M.A. Gadhi, Sh. Fatmi, M.Sh. Gadhi, U. Mahmood, M. Shakil, S.A. Buzdar (2016) Variation of annual effective dose from external ionizing radiation among radiation workers of Bahawalpur Institute of Nuclear Medicine and Oncology (BINO), Pakistan. Int J Radiat Res, 14(3): 229235.

9. Javadi H, Pashazadeh A, Mogharrabi M, Asli I, Tabei F, Parach A, Assadi M (2013) Radiation exposure from diagnostic nuclear medicine examinations in Golestan province. Iran J Nucl Med, 21(2): 65-69.

10. Xiao-San Xu, Lian-An Zhang, Quan-Fu Sun, Yong-Chun Qin, Ning-Le Yu (2018) Estimation of the occupational exposure dose for medical diagnostic X-ray workers in Jiangsu, China, using a retrospective dosimetry method. J Radiat Res, 59(2): 141-148.

11. Al-Abdulsalam A and Brindhaban A (2014) Occupational radiation exposure among the staff of departments of nuclear medicine and diagnostic radiology in Kuwait. Med Princ Pract, 23(2): 129-133.

12. International Commission on Radiation Units and Measurements ICRU (2001) Determination of operational dose equivalent quantities for neutron. ICRU Report 66, Journal of the International Commission on Radiation Units and Measurements 1(3).

13. International Commission on Radiological Protection ICRP (2010) Conversion coefficients for radiological protection quantities for external radiation exposures. ICRP Publication 116, Pergamon Press, Oxford.

14. Kopec R, Budzanowski M, Budzyńska A, Czepczynski R, Dziuk M, Sowinski J, Wyszomirska A (2011) On the relationship between whole body, extremity and eye lens doses for medical staff in the preparation and application of radiopharmaceuticals in nuclear medicine. Radiat Meas, 46(11): 1295-1298.

15. International Commission on Radiological Protection ICRP (2011) Statement on Tissue Reactions ICRP. Ref. 4825- 


\section{Saeed and Almalki / Assessment of the dose and radiogenic risk}

3093-1464, Pergamon Press, Oxford.

16. International Commission on Radiological Protection ICRP (2012) ICRP Statement on Tissue Reactions / Early and Late Effects of Radiation in Normal Tissues and Organs Threshold Doses for Tissue Reactions in a Radiation Protection Context. ICRP Publication 118, Pergamon Press, Oxford.

17. Sulieman A, Yousif E, Alkhorayef M, Mattar E, Babikir E, Bradley D (2018) Lens dose and radiogenic risk from ${ }^{99 \mathrm{~m}} \mathrm{Tc}$ nuclear medicine examinations. J Radioanal Nucl Chem, 318: 797-801.

18. International Commission on Radiation Protection ICRP (1999) Radiation dose to patients from radiopharmaceuticals: Addendum to ICRP 53. ICRP Publication 80, Pergamon Press, Oxford.

19. Nassef MH and Kinsara AA (2017) Occupational Radiation Dose for Medical Workers at a University Hospital. Journal of Taibah University for Science 11:1259-1266.

20. Tsapaki V, Kottou S, Vano E, Parviainen T, Padovani R, Dowling A, Molfetas M, Neofotistou V (2005) Correlation of patient and staff doses in interventional cardiology. Radiat Prot Dosim, 117(1-3): 26-29.

21. Lanca $L$ and Silva A (2013) Digital Imaging Systems for Plain Radiography, Springer-Verlag New York, chapter 5, p59, ISBN 978-1-4614-5067-2.

22. Hart D and Wall BF (2002) Radiation exposure of the UK population from medical and dental x-ray examination. NRPB-W4.

23. Masood K, Ahmad M, Zafar J, et al. (2012) Assessment of occupational exposure among pakistani medical staff during 2007-2011. Australas Phys Eng Sci Med, 35(3): $297-$ 300.

24. Hasford F, Owusu-Banahene J, Amoako JK, et al. (2012) Assessment of annual whole-body occupational radiation exposure in medical practice in Ghana (2000- 2009). Radiat Prot Dosim 149(4): 431- 437.

25. Weizhang W, Wenyil Z, Ronglin C, et al. (2005) Occupational exposures of Chinese medical radiation workers in 1986-2000. Radiat Prot Dosim, 117(4): 440-3.

26. Kamenopoulou V, Drikos G, Dimitriou P (2000) Occupational exposure to ionising radiation in Greece (19941998). Radiat Prot Dosim, 91(4): 385-389.

27. Piwowarska-Bilska $H$, Birkenfeld $B$, Listewnik $M$, et al. (2010) Long-term monitoring of radiation exposure of employees in the department of nuclear medicine (SZCZECIN, POLAND) in the Years 1991-2007. Radiat Prot Dosim, 140(3): 304-7.

28. Covens P, Berus D, Buls N, Clerinx P, Vanhavere F (2007) Personal dose monitoring in hospitals: global assessment, critical applications and future needs. Radiat Prot Dosim, 124(3): 250-9. 